\title{
Absence of Chronic Human Immunodeficiency Virus Infection without Seroconversion in Intravenous Drug Users: A Prospective and Retrospective Study
}

\author{
Sabine Yerly, Eric Chamot, Jean-Jacques Déglon, \\ Bernard Hirschel, and Luc Henri Perrin
}

\author{
Central Laboratory of Virology. Division of Infectious Disease, and \\ Medical Oupatient Clinic, Geneva University Hospital, and \\ Ermitage Therapeutic Center, Geneva, Switzerland
}

\begin{abstract}
It has been reported that human immunodeficiency virus type 1 (HIV-1) infection may exist in persons without specific antibodies for years. To measure the frequency of a silent carrier state, a study was conducted in a cohort of 124 intravenous drug users (IVDUs) without anti-HIV-1 antibodies. All the participants had engaged in high-risk behavior for HIV-1 transmission for a number of years until 1987 or later. Samples were analyzed at 6-month intervals for the presence of HIV-1 provirus using DNA amplification and for the appearance of anti-HIV-1 antibodies. HIV-1 provirus and antibodies were undetectable in 122 participants, whereas seroconversion was observed in 2. In one of these, both amplified HIV-1 pol gene segment and anti-HIV-1 antibodies were detected simultaneously, and in the other, provirus was detected 1 month before seroconversion. This study suggests that long-term HIV-1 infection without anti-HIV-1 antibodies is rare and that repeated antibody testing is sufficient to determine the HIV-1 status of a person no longer at high risk for HIV-1 infection.
\end{abstract}

Routine testing to identify infection with human immunodeficiency virus type 1 (HIV-1) is based on the detection of specific antibodies. The detection of antibodies is indirect evidence of infection; direct evidence necessitates detection of either the virus itself or of viral components. This includes viral culture, which is not always positive in persons known to be infected by HIV-1 [1]. Identification of either viral RNA or HIV-1 provirus integrated into the genome of the host provides another option. Detection of the provirus in clinical samples can be achieved by amplification of segments of proviral DNA using the polymerase chain reaction (PCR) [2].

Several investigators have reported PCR-positive, antibody-negative or viral culture-positive, antibody-negative subjects [3-9]. These observations were made not only in cross-sectional studies but also in individuals followed for several months or years $[3,5,6]$. It was therefore postulated that a silent carrier state of HIV-l infection may exist in the absence of antibodies for long periods of time. If true, this might make it virtually impossible to exclude HIV-I infection by antibody testing, even if these antibody tests were negative months to years after exposure to HIV-1 had ceased.

Received 16 May 1991; revised 1 July 1991

Presented in part: VII International Conference on AIDS, Florence, June 1991

Financial support: Swiss Federal Office of Public Health (Cohort Study. Part A); National AIDS Research Program.

Reprints or correspondence: Dr. L. H. Perrin, Central Laboratory of Virology, University Cantonal Hospital, 1211 Geneva 4, Switzerland.

The Journal of Infectious Diseases 1991;164:965-8

(C) 1991 by The University of Chicago. All rights reserved.

$0022-1899 / 91 / 6405-0022 \$ 01.00$
Since 1981, we have followed a cohort of intravenous drug users (IVDUs) on methadone treatment [10]. The aim of the present investigation was to evaluate the existence of silent HIV-I infection in HIV-I-negative IVDUs of this cohort and the concordance between antibodies to HIV-1 and the detection of HIV-I DNA by PCR.

\section{Methods}

Study population. Two hundred sixty-two IVDUs on methadone treatment were recruited in a cohort study concerning HIV-1 infection and viral hepatitis [10]. For the present investigation, seronegative IVDUs were recruited prospectively between May 1988 and November 1989. The follow-up included biannual interviews, physical examination, and laboratory evaluation. In addition, retrospective data and serum samples were available for 1981-May 1988 for most of the participants.

Our study population was composed mainly of male IVDUs (83\%) with a mean age of 28.5 years. All were engaged in highrisk behavior for HIV transmission for years until 1987 or later [10]. At the first visit, 34\% were HIV-1-seropositive. Of the HIV-1-seronegative IVDUs, $64 \%$ had evidence of past hepatitis $\mathrm{B}$ and $68 \%$ of hepatitis $\mathrm{C}$, suggesting a high risk of contracting hematogenous viral infections [11]. In this population, the frequency of injection and needle sharing decreased after 1988 [10]. These data were confirmed for the participants of the present study: almost $50 \%$ continue to inject and occasionally share needles, as verified by interviews.

Control samples were collected from 40 IVDUs with antiHIV- 1 antibodies and from 20 blood donors without anti-HIV1 antibodies.

Serology. Serum specimens were tested for anti-HIV-I antibodies and p24 antigen using commercial EIAs (Abbott Laboratories, North Chicago). Positive EIAs were confirmed by Western blot (Du Pont, Geneva). 
Purification of DNA. Blood $(10 \mathrm{ml})$ was collected in EDTA, and peripheral blood mononuclear cells (PBMC) were isolated on ficoll-hypaque (Pharmacia, Dubendorf, Switzerland). The pellet of PBMC was incubated overnight at $37^{\circ} \mathrm{C}$ in a lysis buffer containing $100 \mathrm{~m} M \mathrm{NaCl}, 50 \mathrm{~m} M$ TRIS-HCl, pH 7.5, $1 \mathrm{~m} M$ EDT A, $0.5 \%$ SDS, and $100 \mu \mathrm{g} / \mathrm{ml}$ proteinase $\mathrm{K}$. After phenol/ chlorofonm extraction, DNA was precipitated with ethanol and resuspended in $300 \mu$ of TE buffer, $\mathrm{pH} 7.4$ (10 $\mathrm{mM}$ Tris, $1 \mathrm{~m} M$ EDTA). The LAV-8E5 cell line, obtained through the AIDS Research and Reference Reagent Programs (Division of AIDS, National Institute of Allergy and Infectious Diseases, Bethesda, MD) was grown in tissue culture as recommended, and DNA was extracted from a pellet of $50 \times 10^{6}$ cells and aliquotted [12].

Amplification. An oligonucleotide primer pair in a conserved 238-bp area of the pol gene was selected: POLl (5'-TGGGTACCAGCACACAAAGG) hybridizes to the minus-strand at position 3734-3753 in HIV BRU and POL2 (5'-ACTTGTCCATGCATGGCTTC) hybridizes to the plus-strand at position 3953-3972. The probe (5'-AATTGGAGAGCAATGGCTAGTGA), which hybridizes at position 3863-3885, was end-labeled with ${ }^{32} \mathrm{P}$.

For amplification of HIV-1 segments of proviral DNA, a thermostable DNA polymerase was used (Amplitaq DNA polymerase; Perkin-Elmer Cetus, Norwalk, CT) [2] with $5 \mu \mathrm{g}$ of genomic DNA per test and 37 cycles of amplification [13].

One-fifth volume of denatured PCR product was applied to nylon membrane (GeneScreen Plus; NEN, Boston) using a vacuum filtration apparatus (Minifold II; Schleicher \& Schuell, Keene, NH). Filters were incubated for $1 \mathrm{~h}$ at $45^{\circ} \mathrm{C}$ in prehybridization solution $(4 \times$ SSC, $5 \times$ Denhardt's solution, $5 \%$ SDS, $20 \mathrm{~m} M$ sodium phosphate, $\mathrm{pH} 7,100 \mu \mathrm{g} / \mathrm{ml}$ sheared and denatured salmon sperm DNA; $1 \times \mathrm{SSC}=0.15 M$ sodium chloride and $0.015 \mathrm{M}$ sodium citrate) and hybridized to a ${ }^{32} \mathrm{P}$-labeled probe $\left(3 \times 10^{5} \mathrm{cpm} / \mathrm{ml}\right)$ by incubation at $50^{\circ} \mathrm{C}$ overnight. Then filters were washed for $15 \mathrm{~min}$ at $50^{\circ} \mathrm{C}$, once with $3 \times \mathrm{SSC}$ and $0.1 \%$ SDS, once with $0.5 \times$ SSC and $0.1 \%$ SDS, then twice with $0.1 \times$ SSC and $0.1 \%$ SDS. Autoradiographs were obtained after 3 $\mathrm{h}$ and overnight exposure of X-Omat film (Kodak, Lausanne, Switzerland) with an intensifying screen at $-70^{\circ} \mathrm{C}$. Southern blot analysis was done as described [13].

Positive controls for the PCR included serially diluted DNA of the LAV-8E5 cell line containing a single integrated copy of HIV- 1 proviral DNA. Dilutions were adjusted to $5 \mu \mathrm{g}$ of genomic human DNA (DNA purified from human white blood cells). Other controls included buffer and DNA samples from seronegative blood donors and seropositive IVDUs. Purification of DNA, preparation of samples for PCR, and analysis of amplified products were done at three physically separated sites.

\section{Results}

We have shown previously that by using PCR and the pol primers, it was possible to identify $\mathrm{HIV}-1$ pol DNA in all 40 subjects with anti-HIV-I antibodies [13]. In the present study, genomic DNA from 40 IVDUs with anti-HIV-1 antibodies was amplified; all of them were pol DNA-positive on dot blot and Southern blot, but none of the genomic DNA from normal blood donors gave a positive pol DNA signal.
To measure the sensitivity of the system, DNA extracted from the LAV-8E5 cell line containing one copy of HIV-1 provirus per cell was purified and serially diluted in human genomic DNA to obtain 1-1000 LAV-8E5 cells per PCR reaction (figure 1 , left). The sensitivity of the system was such that one copy could be detected: A positive signal was always detected in 15 successive experiments using the control DNA corresponding to $3 \mathrm{LAV}-8 \mathrm{E} 5$ cells and, in most instances, the sample containing DNA corresponding to 1 infected cell. In addition, experiments were done on multiple samples containing amounts of control positive DNA (LAV-8E5) corresponding statistically to $1,0.3$, and 0.1 infected cells (figure 1, right). The results suggest that the sensitivity of the system is of the order of one provirus copy per test and that variations in positivity reflect Poisson distribution.

Initially, 155 IVDUs without anti-HIV-I antibodies were included in the study, but some of them did not participate in the follow-up and were excluded. A positive pol PCR signal was not observed in any of the excluded participants.

One hundred twenty-four IVDUs on methadone treatment without anti-HIV-I antibodies were tested at regular intervals. The length of follow-up for serology and the PCR results are reported in table 1 . PCR was done twice or more in 87 participants and once in 37 participants. In this last group, participants had at least one negative serologic result

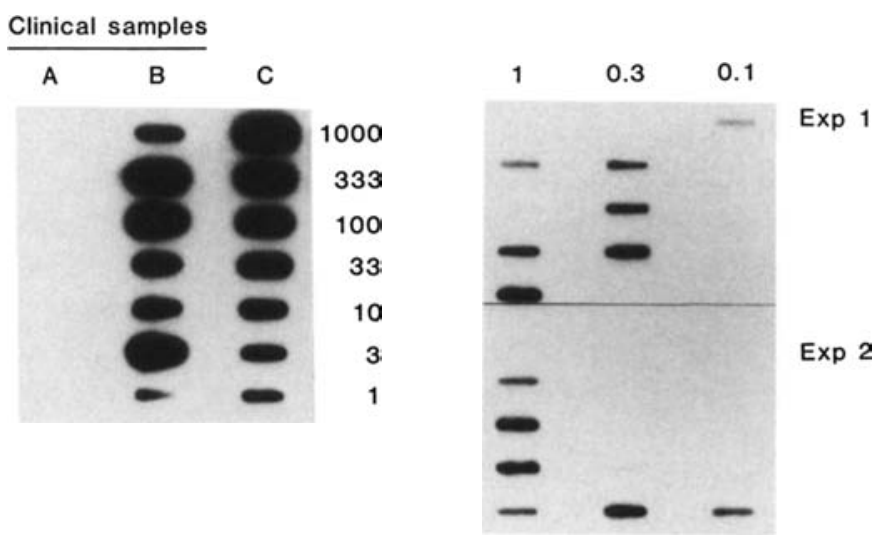

Figure 1. Detection of amplified human immunodeficiency virus type 1 (HIV-1) DNA by autoradiography in clinical samples and determination of sensitivity of amplication using DNA from HIV-1-infected cell line. Left: lane A, top to bottom, samples from four seronegative intravenous drug users (IVDUs), two blood donors, and buffer control; lane B, samples from seven seropositive IVDUs (number of copies in relation to curve established in reference to lane $C$ varied from $>10,000$ to 1 for 40 samples tested; bottom sample in lane B was only sample with $<3$ copies $/ 7 \times 10^{5}$ peripheral blood mononuclear cells); lane C, LAV-8E5 cell line diluted in $5 \mu \mathrm{g}$ of human genomic DNA to number of cell equivalents per sample as listed at right of lane. Right: results of two experiments in which 10 samples containing $1,0.3$, and 0.1 cell equivalent of LAV-8E5 cell line were added to $5 \mu \mathrm{g}$ of human genomic DNA from seronegative blood donor before DNA amplification. 
Table 1. Follow-up testing by serology and polymerase chain reaction (PCR) in 124 intravenous drug users.

\begin{tabular}{lccc}
\hline & & \multicolumn{2}{c}{ Last PCR result } \\
\cline { 3 - 4 } First-known & & Negative & Positive \\
\hline negative EIA & No. $(\%)$ & 36 & 0 \\
Before 1983 & $36(29)$ & 8 & 0 \\
$1984-1985$ & $8(6.5)$ & 19 & 0 \\
$1986-1987$ & $19(15)$ & 46 & 2 \\
1988 & $48(39)$ & 13 & 0 \\
1989 & $13(10.5)$ & 122 & 2 \\
\multicolumn{1}{c}{ Total } & 124 & & \\
\hline
\end{tabular}

6 months before entrance into the study and one 6 months after the PCR analysis. In 122 of 124 participants, both serology and $P C R$ reactions were negative.

During the observation period, two participants seroconverted. For one, PCR was positive in the first available DNA sample. At that time anti-HIV-1 antibodies were not detectable and p24 antigen was slightly positive at $5 \mathrm{pg} / \mathrm{ml}(3 \mathrm{pg} /$ $\mathrm{ml}$ is the detection limit of the p24 antigen assay). Anti$\mathrm{HIV}-\mathrm{l}$ antibodies and $\mathrm{p} 24$ antigen were absent on a serum sample collected 6 months before (no lymphocyte samples were available at this time for PCR analysis). Anti-HIV-I antibodies appeared 1 month after PCR positivity. For the other seroconverter, PCR and serology (antibodies and p24 antigen) were negative at the first and second examinations (months 6 and 12), but both anti-HIV-I antibodies and PCR became positive at 18 months. No symptoms of acute HIV-1 infection were recorded by the two seroconverters except an episode of tiredness in the second patient 3 months before the detection of anti-HIV-1 antibodies. In this patient, p24 antigen was never detectable.

In addition, seven patients that did not participate in the present study have so far been found in our laboratory to be pol DNA-positive before the appearance of detectable antiHIV-1 antibodies (two of them had negative PCR results on samples collected 2 weeks and 3 months before the collection of the PCR-positive samples). All these patients, like the two IVDUs of the present study, developed anti-HIV-I antibodies within 3 months after a PCR-positive result (data not shown).

\section{Discussion}

One objective of the present study was to evaluate the existence of chronic HIV-1 infection using DNA amplification of segments of the pol gene of HIV-1 provirus in a cohort of IVDUs without detectable anti-HIV-1 antibodies. The pol oligonucleotides were selected as primers on the basis of their low degree of sequence variation, which was less than that of more widely used primers corresponding to other HIV-I genes $[2,13,13 \mathrm{a}]$.

Association between anti-HIV-l antibody status and the results of DNA amplification was excellent. All 40 IVDUs with antibodies to HIV-1 had a positive pol PCR result, and none of the 20 seronegative blood donors had a positive pol PCR result. Of 124 seronegative IVDUs, 122 had repeatedly negative results for both pol PCR and anti-HIV-1 antibodies. For the two participants who seroconverted during the study, there was a discrepancy between serology and pol PCR for one of them, but concordant results were observed 1 month later. The results in the two seroconverters of the present study and in the seven patients found in our laboratory to be PCR-positive before appearance of antibodies indicate as expected that PCR can detect HIV-1 infection before the appearance of anti-HIV-l antibodies, but the delay between detection of the provirus and appearance of specific antibodies was, when measurable, $<6$ months. In one seroconverter, the infection was probably due to sexual contacts, as his regular partner is infected by HIV-1; in the other, intermittent use of heroin with needle-sharing seems more likely [10]. Almost $50 \%$ of the participants of the present investigation continue to inject occasionally.

Discrepant results have been reported on seronegative subjects belonging to high-risk groups: Imagawa et al. [3] and others $[5,8]$ have reported that proviral carriage, without specific antibodies, was common. Other investigators were unable to demonstrate HIV-l infection in antibody-negative sex partners of HIV-1-infected hemophiliacs [14] or in antibody-negative homosexual and bisexual men [15]. On a larger basis, the present investigation suggests that persistent HIV-I infection without the subsequent development of specific antibodies is uncommon in a population of IVDUs. The discrepant results reported can be partly related to differences in methodologies, in the recruitment of participants, and in the length of follow-up. However, one has also to consider the possible contamination of negative samples by amplified segments of HIV-l-positive samples or by the virus itself, isolation of which requires at least 10 days of culture and numerous manipulations.

In addition, the failure to identify HIV-1 may be related to several factors. First, the IVDUs may have been recently infected; however, ours was a cohort study in which most subjects were followed for 2 years. Second, the virus may be present below the treshold of detection by PCR. The system used reproducibly detects $\leqslant 3$ copies of HIV-1 provirus in $7 \times$ $10^{5}$ cells, meaning that the limit of sensitivity is $3-15 \mathrm{HIV}-1$ provirus copies $/ \mathrm{ml}$ of blood. Repeatedly negative results lower the theoretical limit of detection. DNA amplification was carried out on PBMC and it is not possible to exclude that other cell types are latently infected. However, many data suggest that CD4 is the main host cell of HIV-l. Finally, we used only one pair of primers within the pol gene, and some individuals may harbor HIV-1 strains whose genome does not hybridize to the primers selected. This is unlikely, because it has been shown previously [13] and confirmed here that the pol primer pair selected could amplify HIV pol 
DNA segments in all HIV-l-seropositive persons tested. Also, the sequences of the primers selected are highly conserved in 17 known HIV-1 sequences [13a].

In summary, the data presented here indicate that longterm silent HIV infection is rare and that repeatedly negative antibody testing (probably within a 6 -month period) after the last exposure is a convincing argument against HIV-I infection.

\section{Acknowledgments}

We thank the participants of the study and the medical staff of the AIDS Unit: J. Wintsch, C. F. Robert, D. Bierens-de Haan, J. L. Martin, B. Broers, O. Ciaroni, D. Sierro, P. Vanhems, C. Junet, C. L. Chaignat, and A. Perrier. We also thank V. Gabriel and $P$. Richard for valuable advice in data processing, K. Zollinger and $P$. Schreiber for expert technical assistance, and $C$. Brown for manuscript preparation.

\section{References}

1. Schneweis KE, Ackermann A, Friedrich A, et al. Comparison of different methods for detecting human immune deficiency virus in human immunodeficiency virus-seropositive hemophiliacs. J Med Virol 1989:29:94-101.

2. Ou CY, Kwok S, Mitchell SW, et al. DNA amplification for direct detection of HIV-1 in DNA of peripheral blood mononuclear cells. Science 1988;239:295-7.

3. Imagawa DT, Lee MH, Wolinsky SM, et al. Human immunodeficiency virus type 1 infection in homosexual men who remain seronegative for prolonged periods. N Engl J Med 1989:320:1458-62.

4. Ameisen JC, Guy B, Lecocq JP, et al. Persistent antibody response to the HIV-1 negative regulatory factor in HIV-I-infected seronegative persons. N Engl J Med 1989;320:251-2
5. Ranki A. Valle SL, Krohn M, et al. Long latency precedes overt seroconversion in sexually transmitted human-immunodeficiency-virus infection. Lancet 1987;2:589-93.

6. Wolinsky SM, Rinaldo CR, Kwok S, et al. Human immunodeficiency virus type 1 (HIV-1) infection a median of 18 months before a diagnostic Western blot. Ann Intern Med 1989;111:961-72.

7. Horsburgh CR, Ou CY, Jason J, et al. Concordance of polymerase chain reactions with human immunodeficiency virus antibody detection. J Infect Dis 1990;162:542-5.

8. Ensoli F, Fiorelli V, Mezzaroma I, D’Offizi GP, Aiuti F. Proviral sequences detection of human immunodeficiency virus in seronegative subjects by polymerase chain reaction. Mol Cell Probes 1990;4:15361 .

9. Horsburgh CR. Ou CY, Jason J, et al. Duration of human immunodeficiency virus infection before detection of antibody. Lancet 1990;2:637-41.

10. Robert CF, Deglon JJ, Wintsch J, et al. Behavioural changes in intravenous drug users in Geneva: rise and fall of HIV infection, 19801989. AlDS 1990;4:657-60.

11. Chamot E, Hirschel B, Wintsch J, et al. Loss of antibodies against hepatitis $C$ virus in HIV seropositive iv drug users. AIDS 1990;4:1275-7.

12. Folks TM. Powel D, Lightfoote M, et al. Biological and biochemical characterization of a cloned $\mathrm{LEU}-3^{-}$cell surviving infection with the acquired immune deficiency syndrome retrovirus. J Exp Med $1986 ; 164: 280-90$.

13. Perrin LH, Yerly S. Adami N. et al. Human immunodeficiency virus DNA amplification and serology in blood donors. Blood 1990;76:641-5.

13a. Human retroviruses and AIDS 1990 database. Los Alamos, NM: Theoretical Biology and Biophysics Laboratory, 1990.

14. Jason J, Ou CY, Moore JL, Dale NL, Schochetman G, Evatt BL. Prevalence of human immunodeficiency virus type I DNA in hemophilic men and their sex partners. J Infect Dis 1989;160:789-94.

15. Lifson AR, Stanley M, Pane J, et al. Detection of human immunodeficiency virus DNA using the polymerase chain reaction in a well-characterized group of homosexual and bisexual men. J Infect Dis $1990 ; 161: 436-9$ 